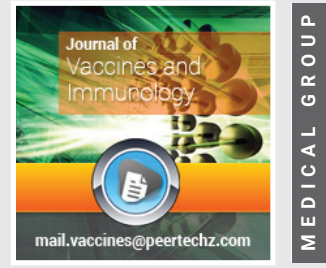

\title{
Going Along the Direction of Trained Immunity - a Herbal Supplement for the Prevention of Respiratory Infection
}

Received: 31 October, 2020

Accepted: 09 November, 2020

Published: 10 November, 2020

*Corresponding author: Ping-Chung Leung, State Key Laboratory of Research on Bioactivities and Clinical Applications of Medicinal Plants, Chinese University of Hong Kong, Hong Kong, E-mail: pingcleung@cuhk.edu. hk; kfcheng@cuhk.edu.hk

Keywords: Herbal supplement; Innate immunity

https://www.peertechz.com

\section{Check for updates}

\section{Ben CL Chan', Ping-Chung Leung ${ }^{1,2 *}$, William KF Cheng', Zhixiu Lin ${ }^{3}$, Edwin $\mathrm{CL} \mathrm{Yu}^{4}$, Ida MT Chu', Ping Chook', Carmen YS Fong ${ }^{1}$ and Chun-Kwok Wong ${ }^{1,5}$}

${ }^{1}$ Institute of Chinese Medicine, The Chinese University of Hong Kong, Hong Kong

${ }^{2}$ State Key Laboratory of Research on Bioactivities and Clinical Applications of Medicinal Plants, Chinese University of Hong Kong, Hong Kong

${ }^{3}$ School of Chinese Medicine, The Chinese University of Hong Kong, Hong Kong

${ }^{4}$ Hong Kong Association for Integration of Chinese-Western Medicine Limited, Hong Kong

${ }^{5}$ Department of Chemical Pathology, Chinese University of Hong Kong, Hong Kong

\begin{abstract}
This is a report of a clinical attempt on the creation of an evidence-based herbal supplement for the personal protection against respiratory infection including COVID-19. The herbal supplement was derived from ancient Chinese herbal formulae. It had been proven safe and effective as a preventive agent during the 2003 SARS epidemic in Hong Kong. It was used again in this pandemic for the same purpose: offering extra personal protection for the frontline medical workers. While appreciations related to apparent preventive effects had been plentiful, a repetition of trial offered to a smaller group of 700 individuals was carried out. Apart from the need for the confirmation of safety and better quality of life, a subgroup of 33 volunteers offered to have their sera checked for immunological boosting effects as had been claimed. Results showed that the two weeks' herbal supplement did achieve a clear indication of boosted immunological defense via a macrophage orientated pathway as was indicated in the changes in chemokine activities. This effects could be understood as a demonstration of "trained immunity" process.
\end{abstract}

\section{Introduction}

During the Pandemic, medical front line workers are at extra-risks: all of them are very much aware of the importance of self-protection and fervently practice personal preventive measures like keeping facial masking, social distancing, and insistence on physical exercises and nutritional supports, from vitamins, e.g. vitamin D to special supplements [1]. However, until an effective vaccine is available the extra-risks remain real and threatening. They all yearn for some effective supplement that could help them to acquire better effective personal protection [2].
In the Chinese Community long tradition has existed and prevailed for the consumption of herbal medicine as preventive and therapeutic agents under epidemic situations, particularly for the frequent prevalence of respiratory infection [3]. Indeed, since the start of the COVID-19 pandemic, Health Authorities and experts in China have been reporting on the successful applications of complicated traditional herbal formulations for the treatment of the COVID-19 patients in the hospital and outside. Emphasis has been put on their therapeutic uses, not specifically under the preventive category [4]. However, it is understood that in the community, people have been making their free choices, according to their closest recommendations. 
They would take some simple herbal combinations for granted as of preventive value.

We respect "folk practice" as useful interventions as long as no known adverse effects are known. At the same time, we believe that we need to produce the evidence of efficacy which can be obtained with laboratory and clinical studies. Now that an effective vaccine for COVID-19 is yet to be available, creating an evidence-based herbal supplement for the general personal protection of the concerned people, particularly the frontline workers and close contacts of the infected, would be of special value.

\section{The SARS experience in 2003}

In the spring of 2003, Hong Kong and mainland China were the foci of a new respiratory infection of viral origin, labeled by the World Health Organization (WHO) as Severe Acute Respiratory Syndrome (SARS). Hong Kong alone, reported 1755 infected cases (Chinese Center for Disease Prevention and Control, 2003).

One unique feature of SARS was that hospital workers were particularly prone to infection; the first outbreak at the Prince of Wales Hospital involved 69\% hospital workers. Subsequently, a total of 360 hospital workers, i.e. $20.5 \%$ of all cases in Hong Kong, were reported.

We created a herbal formula, not for treatment, but for prevention: i.e. for the boosting of innate immunological ability against SARS [5]. The formula consisted of two parts: part one was supportive of "Qi" and part two was a simple herbal combination advocated for mild symptoms (which to our mind, meant prevention of progress) "Qi" was an important ancient concept of balance and harmony which we took as prevention of deficiency in immunological defense.

We organized a clinical trial using the innovative herbal formula for two weeks. Over 2,000 volunteers participated. Subsequent, analysis showed o infection rate, and no serious adverse effects, compared with a $0.4 \%$ infection among those not taking the formula [5].

35 of the herbal group had their blood samples taken before and after the herbal consumption which lasted two weeks for cellular studies targeting on CD4/ CD8 ratio and cell counts of $\mathrm{T}$ and $\mathrm{B}$ cells. The results showed a trend of improvement of $\mathrm{CD} 4 / \mathrm{CD} 8$ ratio. Unfortunately, cytokine studies were not done because of shortage of resources. However, the convincing results gave us a lot of encouragement to continue research on the Preventive Aspect of the herbal products we used.

\section{The current pandemic}

Hong Kong was affected at an early stage in February 2020, but did not reach the severity of the 2003 SARS level. Frontline medical workers however have been under extreme distress for obvious reasons.

We intended to offer them on a smaller scale the same herbal formula we provided in 2003 for their personal protection. A local herbal manufacturer supplied the preparation for the frontline workers as a gift to show its sincere determination of support and respect. 700 two-week doses were provided for the registrants keen to experience the effects of the herbal supplement. We organized a quasi-clinical trial applying the standard requirements of a phase 3 trial. Phase 3 because safety and dosage could be taken for granted, since the herbal combination was derived from two traditional herbal formulae used freely and safely in general households, and we adopted a dosage recommended since the formulae's ancient use. This time, the supplement was expected to be further tested for its preventive effects as would be revealed in the result of clinical observations, as well as clinical immunological responses among a selected group who agreed for serological testing.

The following gives a summary of the two months' long Quasi-clinical trial.

A total of 670 volunteers were received, average aged 45.3(19 to 84 ). There was a female majority of $85.8 \%$ (mostly nurses). Volunteers were required to fill up a simple self-evaluation chart pertaining to quality of life, expressed as general wellbeing physically and mentally; cold-heat responses to changing temperature; sleep and bowel conditions. They were advised to report by phone on adverse conditions and send back a simple report after completion of supplement intake after two weeks.

33 volunteered to have their blood checked for immunological responses and they provided $3 \mathrm{cc}$ of venous EDTA blood through venipunctures at the start, on completion, and 2 weeks after completion ( 25 volunteers).

\section{Herbal supplement}

The herbal preparation was an innovative product prepared in the form of sachets, in a laboratory of GMP standard basing on two classical, popularly used formulae for treating influenza-like diseases. It was a combination of Sang Ju Yin (SJY) and Yu Ping Feng San (YPFS), plus two other herbs with well-known antiviral properties. (Details of the herbs are given under the Reference Section).

\section{Immunological study}

Owing to the limited resources and the extremely busy schedule of the hospital laboratory for immunological assessments during the pandemic, full investigations on a larger scale and comprehensive involvements would not be possible. A practical arrangement aiming at crucial objective data on the immunological value of the herbal supplement was followed instead. Blood samples from the 33 volunteers could not have demanded urgent study on the cellular responses. Instead, the samples were stored up properly for cytokine and chemokine studies when laboratory manpower could be spared.

The selection of immunological markers included

i. Cytokines closely related to inflammation, IL-12p70, TNF- $\alpha$, IL-10, IL-6, and IL-1 $\beta$.

ii. Chemokine closely related to cellular responses, viz. IP10, MCP-1, MIG, RANTES and IL-8 [6-10]. 


\section{Quantification of cytokine and chemokine concentra- tions in the blood samples}

Measurement of plasma cytokines and chemokines in EDTA blood samples from the tested subjects started by immersing them in ice and transporting immediately to the laboratory for processing. EDTA plasma were separated by centrifugation (2000 $\mathrm{g}$ for $10 \mathrm{~min}$ ) at $4^{\circ} \mathrm{C}$ and stored in $3 \mathrm{ml}$ aliquots at $-70^{\circ} \mathrm{C}$ until analysis. Plasma concentrations of IL-1 $\beta$, IL-6, IL-8, IL10, IL-12p70, TNF- $\alpha$, IP-10, MCP-1, MIG and RANTES were quantified with a Human cytokine/chemokine cytometric bead array (CBA) assay kit (BD Pharmingen, San Diego, CA, USA) by using a four-color BD FACSVia flow cytometer (BD Biosciences Cor., San Jose, CA, USA).

\section{Results}

In spite of the very busy schedule of the hospitals within this extra-ordinary chaotic period of the Pandemic, volunteers took the trial supplements regularly for two weeks and reported back on completion.

No significant adverse effects were recorded. A general feeling of well-being was reported, physically and mentally. Only 15 stopped taking the supplements after a few days for various personal reasons. As far as we checked, none of them was infected.

Although only 33 volunteered to provide their blood for immunological study, the results might be able to give solid indications of the supplement's immunological effects.

\section{Immunological studies}

i. Inflammatory cytokines: IL-12p70, TNF- $\alpha$, IL-10, IL-6, IL-1 $\beta$. All Plasma samples before and after supplement consumption did not reach quantifiable level (Table 1).

ii. Chemokines related to cellular responses (Table 1). IP-10 and MIG showed significant increases after supplement consumption. MCP-1 showed obvious trend of increase. IL- 8 changes did not provide useful data as expected because of its biphasic nature.

\section{Statistical analysis}

Continuous variables were compared using the one way ANOVA to compare pre-, post-treatment and follow-up visits and the data were described as mean (standard deviation). A P value of less than 0.05 was considered to be statistically significant. Statistical analysis was performed using SPSS (Version 25.0 for Windows, SPSS, Chicago, IL) Figure 1.

\section{Discussion}

During the pandemic, frontline medical workers under extreme degrees of stress deserve respect and attention. Community activities at different circles all intend to support with varieties of offers and contributions. Until the effective vaccine becomes a reality, we believe that special items of herbal medicine could be investigated to establish their value as specific protective agents carrying immunological boosting
Table 1: Cytokine and Chemokine levels at each visit.

\begin{tabular}{|c|c|c|c|c|}
\hline & $\begin{array}{c}\text { Pre-treatment } \\
(n=33)\end{array}$ & $\begin{array}{l}\text { Post-treatment } \\
\quad(n=33)\end{array}$ & $\begin{array}{l}\text { Follow-up } \\
(n=25)\end{array}$ & $P$ value \\
\hline Serum IL-12p70 (pg/mL) & $<=1.9$ & $<=1.9$ & $<=1.9$ & \\
\hline Serum TNF-a (pg/mL) & $<=3.7$ & $<=3.7$ & $<=3.7$ & \\
\hline Serum IL-10 (pg/mL) & $<=3.3$ & $<=3.3$ & $<=3.3$ & \\
\hline Serum IL-6 (pg/mL) & $<=2.5$ & $<=2.5$ & $<=2.5$ & \\
\hline Serum IL-1 $\beta(\mathrm{pg} / \mathrm{mL})$ & $<=7.2$ & $<=7.2$ & $<=7.2$ & \\
\hline Serum IP-10 (pg/mL) & 235.9609 & $1460.8404^{\star \star}$ & $3294.3530 * \star$ & 0.001 \\
\hline Serum MCP-1 (pg/mL) & 22.8853 & 26.3203 & 35.7085 & 0.675 \\
\hline Serum MIG (pg/mL) & 62.1295 & 112.9548 & $259.4128 *$ & 0.001 \\
\hline Serum RANTES $(\mathrm{pg} / \mathrm{mL})$ & 7413.6941 & $5099.2533^{\star}$ & 5910.8725 & 0.015 \\
\hline Serum IL-8 (pg/mL) & 10.0506 & 6.9613 & 5.7406 & 0.485 \\
\hline
\end{tabular}

effects [11]. Our group has worked and reported on such effects related to respiratory infections and cancer protection $[12,13]$

We are extremely grateful to the Herbal Manufacturer which provided us free supplements for 700 volunteers to be used as additional personal protective agents. This great deed also allowed us to further investigate the clinical effects of the herbal formula we used in the SARS epidemic [5] and we are happy to report that the formula was safe, and gave subjective improvements in the general aspects of Quality of Life.

We ventured to explore the immunological boosting effects of the supplement. We believe that the supplement could have vaccine-like effects which are more related to the macrophage orientation as $\beta$ glucan has been reported widely. Indeed, immunological boostings in the direction of innate-immunity are well known for a variety of medicinal herbs which could contain glucan-related molecules [14-17].

To our great satisfaction, using limited target markers of cytokines and chemokines, we found the supplement to be supportive and possibly initiative for cellular responses in innate-immunological defense. The changes in the immune-markers appear to support the $\mathrm{T}$ helper type 1 (Th1) and macrophage orientated defense activities against invading organisms, as has been described under the "trained Immunity" discussions.

Through the control of the migration and positioning of immune cells in tissues, chemokines are essential chemotactic mediators of inflammation and important for the control of viral infections $[18,19]$. In general, increases in circulating chemokines may attract more immune cells in the blood in response to infections. We found significant increases of Th1related IP-10/CXCL10 and monokine induced by interferon- $\gamma$ (MIG)/CXCL9 in our study.

The herbal supplement boosted up the innate immunity by enhancing significantly the production of two chemokines IP-10 (CXCL10) and MIG, without significant induction of inflammatory activities (induction of inflammatory cytokines: $\mathrm{IL}-1 \beta, \mathrm{IL}-6$ and $\mathrm{TNF} \alpha$ ) during the testing period. 

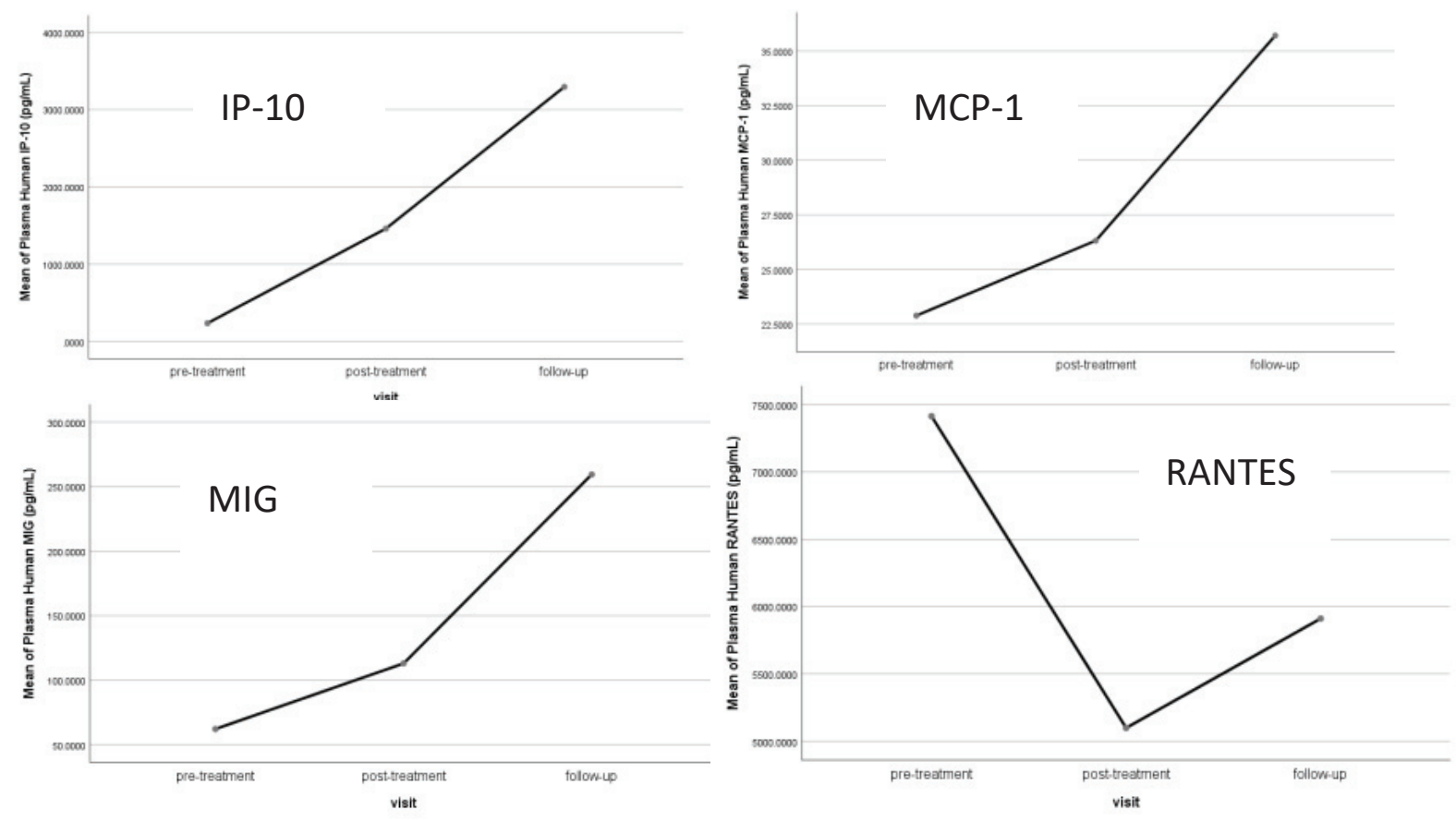

Figure 1: Plasma concentrations of IP-10 and MIG showed significant increases after supplement consumption. MCP-1 showed obvious trend of increase. RANTES showed significant decrease after the first two weeks.

IP-10 and MIG are essential for Th1 cell recruitment and that induction of the two chemokines occurs concomitant to production of interferon (IFN)- $\Upsilon[20,21]$.

Although IP-10 may either protect or promote infection, depending on host immune status and genetic background [14], IP-10 has been shown to be protective in coronavirus (CoV)induced severe acute respiratory syndrome (SARS) [22,23].

Recent findings in the field of immune memory have demonstrated that $\mathrm{B}$ and $\mathrm{T}$ cell mediated immunity following infections are enhanced by the so-called "trained immunity". This effect has already been investigated for the tuberculosis vaccine strain Bacillus Calmette-Guerin (BCG) [24]. Upon infection or vaccination, monocytes/macrophages can be functionally reprogrammed so as to display an enhanced defensive response against unrelated infections.

It is suggested that this protective effect is mediated by a BCG-induced increase in the function of innate immune cells, including higher pro-inflammatory cytokine responses to secondary unrelated pathogens. This process is mediated by transcriptomic and epigenetic changes of myeloid cells, such as monocytes and macrophages [25]. Monocytes can develop immunological memory, a functional characteristic widely recognized as innate immune training, to distinguish it from the memory in adaptive immune cells.

Upon a secondary immune challenge, either homologous or heterologous, trained monocytes/ macrophages exhibit a more robust immune response than untrained monocytes [26]. Similarly, we found that our herbal supplement exhibited significant immunomodulating effects by enhancing the chemokines production from immune cells.
Natea developed the concept of "Trained Immunity" through epidemiological observations that people after commonplace vaccinations like BCG tend to be more resistant to other infections; then a lot of laboratory work confirmed the same phenomenon in experimental animals [27-29]. Convincing observations included, e.g. that "Candida albicans infection affords protection against reinfection via functional reprograming of Monocytes" [30]. Using mice without T and B cells infected with Candida albicans, it was found that they could be protected against re-infection in a monocyte-dependent manner. The functional reprograming of monocytes leading to increased cytokine and chemokine production could be induced by the fungal cell wall $\beta$ glucan [31]. Herbal supplements could have produced the same effects of macrophage orientated, monocyte reprogramming to achieve a realization of "Trained Immunity" [32].

Limitations of this study are obvious. Although chemokines and their receptors are extremely important for the control of a virus infection and replication, the fact that plasma concentrations of IP-10 and MIG showed significant increases after supplement consumption was not sufficient for the proof of antiviral immunological effects. The studied Herbal Supplement had a complex natural origin, including many plant objects, which complicated its standardization. Nevertheless, given the safety of this herbal preparation, the data obtained are of good interest for further studies.

\section{Conclusion}

After two clinical testings: one during the 2003 SARS epidemic; another during the current Pandemic, and related studies on the immunological boosting effects of the herbal supplement, the satisfactory results encourage further 
research commitments: Short term Macrophage Orientated innate defense has been demonstrated, the herbs used like many others may be suitable candidates for studies on Trained Immunity: to explore whether facilitated cells retain the extra defending ability or whether the next generations could still retain the extra properties as if they have been well trained.

\section{Acknowledgment}

This work was supported by the Eu Yan Sang (Hong Kong) Limited and the State Key Laboratory Fund provided by the Innovation and Technology Commission of Hong Kong. We are grateful to the support given us by the Hong Kong Association for Integration of Chinese-Western Medicine Limited (HKAIM).

\section{*The herbal supplement}

Medical Herbs composing the supplement are given as follows:

SJY consisted of the following herbs: Folium Mori, Flos Chrysanthemi, Semen Armeniacae Amarum, Fructus Forsythiae, Herba Menthae, Radix Platycodonis, Radix

Glycyrrhizae, and Rhizoma Phragmitis. YPFS consisted of the following herbs: Radix

Astragali, Radix Saposhnikoviae, and Atractylodes Macrocephala Koidz. Atractylodes

Macrocephala Koidz was excluded. Two antiviral herbs, Folium Isatidis and Radix

Scutellariae, were added. This formula has registered under the local Health Authority as a Health Supplement.

\section{References}

1. Ma Y, Hou L, Yang X, Huang Z, Yang X, et al. (2020) The association between frailty and severe disease among COVID-19 patients aged over 60 years in China: a prospective cohort study. BMC Medicine 18: 274. Link: https://bit. ly/31807uN

2. Chan B, Wong CK, Leung PC (2020) What can we do for the Personal Protection against the CoVID-19 infection? Immuno-boostering Specifi c Supplement could be the Answer. J Emerg Med Trauma Surg Care 2: 007. Link: https:// bit.ly/3I0b1PV

3. Ping-chung L, Chan Chung-lap B, Chun-kwok W (2020) What do we expect from Traditional Chinese Medicine in the COVID-19 Pandemic? Chinese Traditional Medicine Journal 3. Link: https://bit.ly/2S8PmbW

4. Ping-Chung L, Chung-Lap Ben C, Chun-Kwok W (2020) Clinical Use of Chinese Medicine in the Current COVID-19 Crisis and Related Research Planning. Clin Res Infect Dis 5: 1054. Link: https://bit.ly/3i6We3W

5. Lau TF, Leung PC, Wong $\vee(2005)$ Using herbal medicine as a means of prevention: Experience during the SARS crisis. Am J Chin Med 33: 345-356. Link: https://bit.ly/2G20kNY

6. IP-10 - A new marker to detect cellular immune activation. Diag-Info: 247 / Page 1 - 1 / Version: 4. Link: https://bit.ly/3lffoH5

7. Ibrahim ZA (2014) Study of the Serum Level of the Monokine Induced by Interferon Gamma (MIG) in Vitiligo Patients. The Gulf Journal of Dermatology and Venereology 21: 27-32.
8. Dehqanzada ZA, Storrer CE, Hueman MT, Foley RJ, Harris KA, et al. (2006) Correlations between SerumMonocyte Chemotactic Protein-1 Levels, Clinical Prognostic Factors, and HER-2/neu Vaccine-Related Immunity in BreastCancer Patients. Clin Cancer Res 12: 478-486. Link: https://bit.ly/35dqdnA

9. Baer PC, Koziolek M, Fierlbeck W, et al. (2005) CC-Chemokine RANTES Is Increased in Serum and Urine in the Early Post-Transplantation Period of Human Renal Allograft Recipients. Kidney Blood Press Res 28: 48-54. Link: https://bit.ly/3590wmu

10. Al-Dalaan A, Al-Sedairy S, Al-Balaa S, Al-Janadi S, Elramahi K, et al. (1995) Enhanced interleukin 8 secretion in circulation of patients with Behc,et's disease. J Rheumatol 22: 904-907. Link: https://bit.ly/2GLdcZ6

11. Poon PMK, Wong Ck, Fung KP, Fong CYS, Wong ELY, et al. (2006) Immunomodulatory Effects of a Traditional Chinese Medicine With potentia Antiviral Activity: A Self-Control study. Am J Chin Med 34: 13-21. Link: https://bit.ly/2U8GTGy

12. Fung KP, Leung PC, Wong KB, Waye MY, Au WN, et al. (2011) Immunomodulatory activities of the herbal formula Kwan Du Bu Fei Dang in healthy subjects: a randomized, double-blind, placebo-controlled study. Hong Kong Med J 17 S41-S43. Link: https://bit.ly/38o0BGv

13. Chan KW, Wong VT, Tang CW (2020) COVID19: An update on the epidemiological, clinical and guidelines of integrative Chinese-Western medicine for the management of 2019 Novel coronavirus disease. Am J Chin Mediine 48: 737-762. Link: https://bit.ly/3paLDtn

14. Ragupathi G, Yeung KS, Leung PC, Lee M, Lau CBS, et al. (2008) Evaluation of widely consumed botanicals as immunological adjuvants. Vaccine 26: 48604865. Link: https://bit.ly/2InY1oU

15. Hong F, Xiao WL, Ragupathi G, Lau CBS, Leung PC, et al. (2011) The known Immunologically active components of Astragalus account for only a small proportion of the immunological adjuvant activity when combined with conjugate vaccines. Planta Med 77: 817-824. Link: https://bit.ly/3eRVznb

16. Han XQ, Yue GL, Yue RQ, Dong CX, Chan Cl, et al. (2014) Structure elucidation and immunomodulatory activity of a beta glucan from the fruiting bodies of Ganoderma sinense. Plos One 9: e100380. Link: https://bit.ly/38r873G

17. Yue GGL, Chan BCL, Hon PM, Kennelly EJ, Yeung SK, et al. (2010) Immunostimulatory activities of polysaccharide extract isolated from Curcuma longa. Int J Biol Macromol 47: 342-347. Link: https://bit.ly/3lerd0q

18. Arai K, Liu ZX, Lane T, Dennert G (2202) IP-10 and Mig facilitate accumulation of $T$ cells in the virus-infected liver. Cell Immunol 219: 48-56. Link: https://bit.ly/3n3bBgL

19. Liu MT, Armstrong D, Hamilton TA, Lane TE (2001) Expression of Mig (monokine induced by interferon-gamma) is important in $T$ lymphocyte recruitment and host defense following viral infection of the central nervous system. J Immunol 166: 1790-1795. Link: https://bit.ly/3letZmn

20. Liu M, Guo S, Hibbert JM, Jain V, Singh N, et al. (2011) CXCL10/IP-10 in infectious diseases pathogenesis and potential therapeutic implications. Cytokine Growth Factor Rev 22: 121-130. Link: https://bit.ly/2ImvAlp

21. Chen J, Subbarao K (2007) The Immunobiology of SARS*. Annu Rev Immunol 25: 443-472. Link: https://bit.ly/35cxJPx

22. Hsieh YH, Chen CW, Schmitz SF, King CC, Chen WJ, et al. (2010) Candidate genes associated with susceptibility for SARS-coronavirus. Bull Math Biol 72: 122-132. Link: https://bit.ly/3p8D8Pz

23. Gyssens IC, Netea MG (2019) Heterologous effects of vaccination and trained immunity. Clin Microbiol Infect 25: 1457-1458. Link: https://bit.ly/38qQeSg

24. Cirovic B, de Bree LCJ, Groh L, Blok BA, Chan J, et al. (2020) BCG Vaccination in Humans Elicits Trained Immunity via the Hematopoietic Progenitor Compartment. Cell Host Microbe 28: 322-334 e325. Link: https://bit.ly/32sAgTV

Citation: Chan BC, Leung PC, Cheng WK, Lin Z, Yu EC (2020) Going Along the Direction of Trained Immunity - a Herbal Supplement for the Prevention of Respiratory Infection. J Vaccines Immunol 6(1): 032-037. DOI: https://dx.doi.org/10.17352/jvi.000035 
25. Perez-Hernandez CA, Kern CC, Butkeviciute E, McCarthy E, Dockrell HM, et al. (2020) Mitochondrial Signature in Human Monocytes and Resistance to Infection in C. elegans During Fumarate-Induced Innate Immune Training. Front Immunol 11: 1715. Link: https://bit.ly/3n9PcOC

26. Yin JY, Chan BCL, Yu H, Lau IYK, Han XQ, et al. (2012) Separation, structure characterization, conformation and immunomodulating effect of a hyperbranched heteroglycan from Radix Astragali. Carbohyd Polym 87: 667675. Link: https://bit.ly/3papj3d

27. Netea MG, Dominguez-Andres J, Barreiro LB, Chavakis T, Divangahi M, et al (2020) Defi ning training immunity and its role in health and disease. Nat Rev Immunol 20: 375-388. Link: https://bit.ly/3ilH6A1

28. Netea MG, Giamarellos-Bourboulis EJ, Dominguez-Andre's J, Curtis N, van
Crevel R, et al. (2020) Trained Immunity: a tool for reducing susceptibility to, and the severity of SARS-COV-2 Infection. Cell 181. Link: https://bit.ly/2Hwfdbt

29. Van der Meer J, Joosten LAB, Netea Ma (2015) Trained Immunity: A smart way to enhance innate immune defense. Mol Immunol 68: 40-44. Link: https://bit.ly/33cLbSH

30. Quintin J, saeed S, Netea MG (2012) Candida albicans Infection affords Protection against re-infection via Functional Reprogramming of Monocytes. Cell Host Microbe 12: 223-232. Link: https://bit.ly/2U9fhRO

31. Kaminogawa S, Nanno M (2004) Modulation of Immune Functions by Food Evidence-based Comp Alternat Med 1: 241-250. Link: https://bit.ly/2Ik3MV1

32. Netea MG, Quintin J, Vander Meer JW (2011) Trained immunity: a memory for innate host defense. Cell Host Microbe 9: 355-361. Link: https://bit.ly/3jeyR9V

Discover a bigger Impact and Visibility of your article publication with

\section{Peertechz Publications}

\section{Highlights}

* Signatory publisher of ORCID

* Signatory Publisher of DORA (San Francisco Declaration on Research Assessment)

- Articles archived in worlds' renowned service providers such as Portico, CNKI, AGRIS, TDNet, Base (Bielefeld University Library), CrossRef, Scilit, J-Gate etc.

* Journals indexed in ICMJE, SHERPA/ROMEO, Google Scholar etc.

* OAI-PMH (Open Archives Initiative Protocol for Metadata Harvesting)

* Dedicated Editorial Board for every journa

* Accurate and rapid peer-review process

- Increased citations of published articles through promotions

* Reduced timeline for article publication

Submit your articles and experience a new surge in publication services (https://www.peertechz.com/submission).

Peertechz journals wishes everlasting success in your every endeavours.

Copyright: @ 2020 Chan BC, et al. This is an open-access article distributed under the terms of the Creative Commons Attribution License, which permits unrestricted use, distribution, and reproduction in any medium, provided the original author and source are credited.

Citation: Chan BC, Leung PC, Cheng WK, Lin Z, Yu EC (2020) Going Along the Direction of Trained Immunity - a Herbal Supplement for the Prevention of Respiratory Infection. J Vaccines Immunol 6(1): 032-037. DOI: https://dx.doi.org/10.17352/jvi.000035 